\title{
Effect of Using Different Vehicles on the Physicochemical, Antimicrobial, and Biological Properties of White Mineral Trioxide Aggregate
}

\author{
Bruno Cavalini Cavenago, PbD, ${ }^{*}$ Aldo Enrique del Carpio-Perochena, PhD, * \\ Ronald Ordinola-Zapata, PbD, ${ }^{*}$ Carlos Estrela, PbD, ${ }^{\neq}$Gustavo Pompermaier Garlet, PbD, \\ Mario Tanomaru-Filbo, PbD, ${ }^{\|}$Paulo Henrique Weckwerth, PbD, ${ }^{\pi}$ \\ Flaviana Bombarda de Andrade, ${ }^{*}$ and Marco Antonio Hungaro Duarte, PhD*
}

\begin{abstract}
Introduction: This study evaluated the physicochemical, antimicrobial, and biological properties of white mineral trioxide aggregate (MTA) mixed with aqueous and propylene glycol extracts of Arctium lappa L. and Casearia sylvestris Sw. Methods: The settingtime test was performed according to American Society for Testing and Materials 266/2008 and flowability by American National Standards Institute/American Dental Association 57/2012 standard specifications. The following parameters were assessed: volumetric change by micro-computed tomography; $\mathrm{pH}$ level and calcium ion release measured after 3 hours and 1, 3, 7, and 15 days; antimicrobial effect by the dentin decontamination method with intratubular Enterococcus faecalis viability, verified by using confocal laser scanning microscopy; and biocompatibility by histologic-morphometric analyses of inflammatory infiltrate at subcutaneous implant sites after 15,30, and 60 days. In addition, rat alveolar tissues with implants were processed to measure tumor necrosis factor-alpha and interleukin-10 cytokines by enzyme-linked immunosorbent assay. Results: The plant extracts associated with MTA significantly increased the final setting time; however, they did not influence volumetric change $(P>.05)$ and maintained medium alkalinity and calcium ion release. Propylene glycol extracts showed higher flowability. Casearia sylvestris increased the cementing effect against $E$. faecalis after 24 -hour and 168 -hour periods. Histologic evaluation of inflammatory infiltrate showed no significant differences between plant extracts groups and the distilled water group for all periods. Tumor necrosis factor-alpha and interleukin-10 expression
\end{abstract}

was similar among groups $(P>.05)$. Conclusions: Casearia sylvestris extracts increased the antimicrobial effect of MTA and did not influence biocompatibility but changed some physicochemical properties. (J Endod 2017;43:779-786)

\section{Key Words}

Biocompatibility, Enterococcus faecalis, material testing, phytotherapy

Vlineral $\begin{aligned} & \text { trioxide } \\ & \text { aggregate }\end{aligned}$ (MTA), which was developed in the 1990 s as a root-end filling material (1), was selected for this clinical application because of its satisfactory sealing ability $(2,3)$, biocompatibility (4-6), and capacity for stimulating mineralization and repair processes $(6,7)$. However, this cement has shown handling difficulties, extended setting time, possibility of washout $(8,9)$, and limited antimicrobial activity $(10,11)$.

Periapical tissue contamination by bacterial species frequently isolated from secondary endodontic infections (12) must be considered when performing endodontic surgery. Dentin, a mineralized but permeable tissue consisting of dentinal tubules, is colonized and infected by viable bacteria (13) at the time of root-end preparation. The antibacterial properties of root-end filling cements could add benefit by eliminating persistent bacteria from the dentinal tubules. Despite the low antibacterial action reported, there have been no reports in the literature on the potential disinfection of the dentinal tubules provided by MTA.

Some studies $(10,14,15)$ have proposed improved handling of MTA by replacing the distilled water or associating it with antiseptic solutions to add to or enhance the antimicrobial effect of MTA. The addition of $2 \%$ chlorhexidine provided significant increase in activity against Enterococcus faecalis (10), but this mixture increased the cytotoxicity (14) and interfered with the physical properties of MTA (15). In

From the *Department of Operative Dentistry, Endodontics and Dental Materials, School of Dentistry of Bauru, University of São Paulo, Bauru, São Paulo, Brazil; ${ }^{\dagger}$ Department of Restorative Dentistry, Federal University of Paraná, Curitiba, Paraná, Brazil; ' Department of Stomatologic Sciences, Federal University of Goiás, Goiânia, Goiás, Brazil; §Department of Biological Sciences, School of Dentistry of Bauru, University of São Paulo, Bauru, São Paulo, Brazil; "Department of Restorative Dentistry, Araraquara Dental School, São Paulo State University, Araraquara, São Paulo, Brazil; and "Center of Health Sciences, Sagrado Coração University, Bauru, São Paulo, Brazil.

Address requests for reprints to Dr Bruno Cavalini Cavenago, Av. Prefeito Lothário Meissner no. 632, 80210-170 Curitiba, Paraná, Brazil. E-mail address: brunocavenago@hotmail.com

0099-2399/\$ - see front matter

Copyright (c) 2017 American Association of Endodontists.

http://dx.doi.org/10.1016/j.joen.2016.12.023 
general, subcutaneous implantation in rats has shown that white MTA induced severe inflammatory reactions within short periods, which were reduced to chronic infiltrate of moderate to mild intensity over time $(4,5)$.

Plant extracts with antimicrobial properties associated with MTA could act as alternatives. The herbaceous plant Arctium lappa $\mathrm{L}$., originating from Eurasia and found in various regions throughout the world, is commonly used in folk medicine for treating infectious diseases. Another plant, Casearia sylvestris SW., is a common species in Latin America. Both herbal medicines have shown antimicrobial action $(16,17)$ and anti-inflammatory properties (18-20).

However, no studies have reported the effects of phytotherapy products mixed with MTA on its properties. This study proposed to evaluate the physicochemical, antimicrobial, and biological properties of white MTA mixed with aqueous and propylene glycol extracts of Arctium lappa L. and Casearia sylvestris Sw.

\section{Materials and Methods Preparation of Plant Extracts}

The Arctium lappa L. (AL) and Casearia sylvestris Sw. (CS) leaves were harvested in Bauru and Botucatu, respectively, and identified in the Sagrado Coração University herbarium in Bauru, Brazil. The leaves were desiccated in an air-circulating oven at a controlled temperature until constant weight was achieved. A laboratory knife-mill was used to grind the prepared leaves.

Aqueous extracts (AqE) were obtained by diluting $25 \mathrm{~g}$ powdered leaves with $180 \mathrm{~mL}$ distilled water (DW) at $50^{\circ} \mathrm{C}$ for 24 hours. After this time, the solutions were filtered and stored in amber-colored flasks.

Propylene glycol extracts (PglyE) were obtained by macerating $25 \mathrm{~g}$ powdered leaves in $200 \mathrm{~mL}$ extracting solution. This association was maintained at $25^{\circ} \mathrm{C}$ for 8 days, with sporadic agitation in an amber-colored container.

\section{Sample Preparation and Study Design}

White MTA (Angelus, Londrina, Brazil) was mixed with AL-AqE and AL-PglyE and with CS-AqE and CS-PglyE and DW. Cement was manipulated in the ratio of 3 parts powder to 1 part liquid. For ALPglyE and CS-PglyE, the proportions of $20 \%$ PglyE and $80 \%$ DW, respectively, were used.

\section{Setting Time}

\section{Physicochemical Tests}

Setting-time tests were carried out according to American Society for Testing and Materials C266-08 specifications, but samples were made according to the International Organization for Standardization (ISO) 6876:2012 standard. Twenty-five metal rings measuring $10 \mathrm{~mm}$ in diameter and $2 \mathrm{~mm}$ thick were immediately filled with cements $(\mathrm{n}=5)$ and maintained in an incubator at $37^{\circ} \mathrm{C} \pm 1^{\circ} \mathrm{C}$ and $95 \% \pm 5 \%$ humidity.

The initial setting time was determined with a $113.4 \mathrm{~g}$ Gilmore needle at 60-second intervals until the time when no indentations could be verified on the specimen surface. A $453.6 \mathrm{~g}$ Gilmore needle was used in the same manner to determine the final setting time. The times were registered in minutes with a digital chronometer.

\section{Flowability}

Flowability, which was based on the American National Standards Institute/American Dental Association standard no. 57 (2012), was measured by placing $0.5 \mathrm{~mL}$ freshly prepared cement $(\mathrm{n}=3)$ on a glass slab. After 3 minutes, the cement was covered with another glass slab weighing $20 \pm 2 \mathrm{~g}$, and a $100 \mathrm{~g}$ weight was placed on this assembly. The weight and top glass slab were removed after 10 minutes. The samples were photographed with a ruler, which was used as scale for the ImageJ software (National Institutes of Health, Bethesda, MD) to measure the perimeter of digitalized samples. The results are expressed in millimeters.

\section{Volumetric Change}

Fifty acrylic teeth $(\mathrm{n}=10)$ with standardized root-end cavities were filled with the experimental cements by using an MTA carrier device. The specimens were scanned with a desktop x-ray microfocus computed tomography scanner (SkyScan 1174v2; Bruker, Kontich, Belgium). The scanning procedure parameters were as follows: $50 \mathrm{kV}$ x-ray tube voltages, $800 \mu \mathrm{A}$ anode current, voxel size of $9.47 \mu \mathrm{m}$, and $1.0^{\circ}$ rotation step in $360^{\circ}$ rotation. Digital data were elaborated by reconstruction software (NRec-onv1.6.4.8, SkyScan), and CTan software (CTanv1.11.10.0, SkyScan) was used to measure the sample volume $\left(\mathrm{mm}^{3}\right)$.

After the scanning procedures and final setting time, the samples were individually placed in glass flasks containing $15 \mathrm{~mL}$ ultrapure water and stored at $37^{\circ} \mathrm{C}$ for 168 hours. After this time the samples were scanned again by using the same parameters as those adopted for the first scan, sample volumes were measured, and the reduction in volume was calculated and converted into percentage values.

\section{pH Level and Calcium Release}

Fifty acrylic teeth $(n=10)$, prepared in the same manner as those for the volumetric change test, were individually placed in glass flasks containing $10 \mathrm{~mL}$ deionized $\mathrm{DW}$ and stored at $37^{\circ} \mathrm{C}$ for 3 hours and $1,3,7$, and 15 days. After each experimental time, the teeth were transferred to a new flask with $10 \mathrm{~mL}$ ultrapure water. The water in which the specimen was immersed was measured with a pH meter (model 371; Micronal, São Paulo, SP, Brazil) calibrated with known $\mathrm{pH}$ values $(4,7,14)$.

The calcium ion release was measured with an atomic absorption spectrophotometer (AA6800; Shimadzu, Tokyo, Japan) equipped with a calcium ion-specific hollow cathode lamp, according to the protocol cited in a previous study (8). Calcium ion release readouts were compared with a standard curve obtained from readouts of the standard solutions, and data obtained were statistically analyzed.

\section{Antimicrobial Evaluation}

Sixty maxillary bovine incisors were used to obtain 3-mm-long cylindrical dentin samples from the apical section. For standardization, the root canals were prepared up to size $120 \mathrm{~K}$-file (Dentsply Maillefer, Ballaigues, Switzerland). Samples were immersed in $2.5 \% \mathrm{NaOCl}$ and then in 17\% EDTA solution for 5 minutes and finally rinsed with DW. Subsequently, 2 coats of nail varnish were applied on the external root surface. The samples were individually placed in $1.5 \mathrm{~mL}$ microtubes and sterilized at $121^{\circ} \mathrm{C}$.

\section{Dentin Infection and Sample Preparation}

The Enterococcus faecalis (ATCC 29212) culture was obtained by incubation in sterile brain-heart infusion broth (BHI) (Difco, Kansas City, M0) at $37^{\circ} \mathrm{C}$ for 24 hours. The following 5 -day contamination protocol (21) was used.

On day1, the bacterial culture concentration of $3 \times 10^{8}$ colonyforming units $/ \mathrm{mL}$ was standardized by using a spectrophotometer and incubated at $37^{\circ} \mathrm{C}$ for 7 hours to achieve exponential growth. Each microtube containing a dentin cylinder received $800 \mu \mathrm{L}$ sterilized $\mathrm{BHI}$ and was shaken in an ultrasonic bath for 15 minutes. The BHI was 


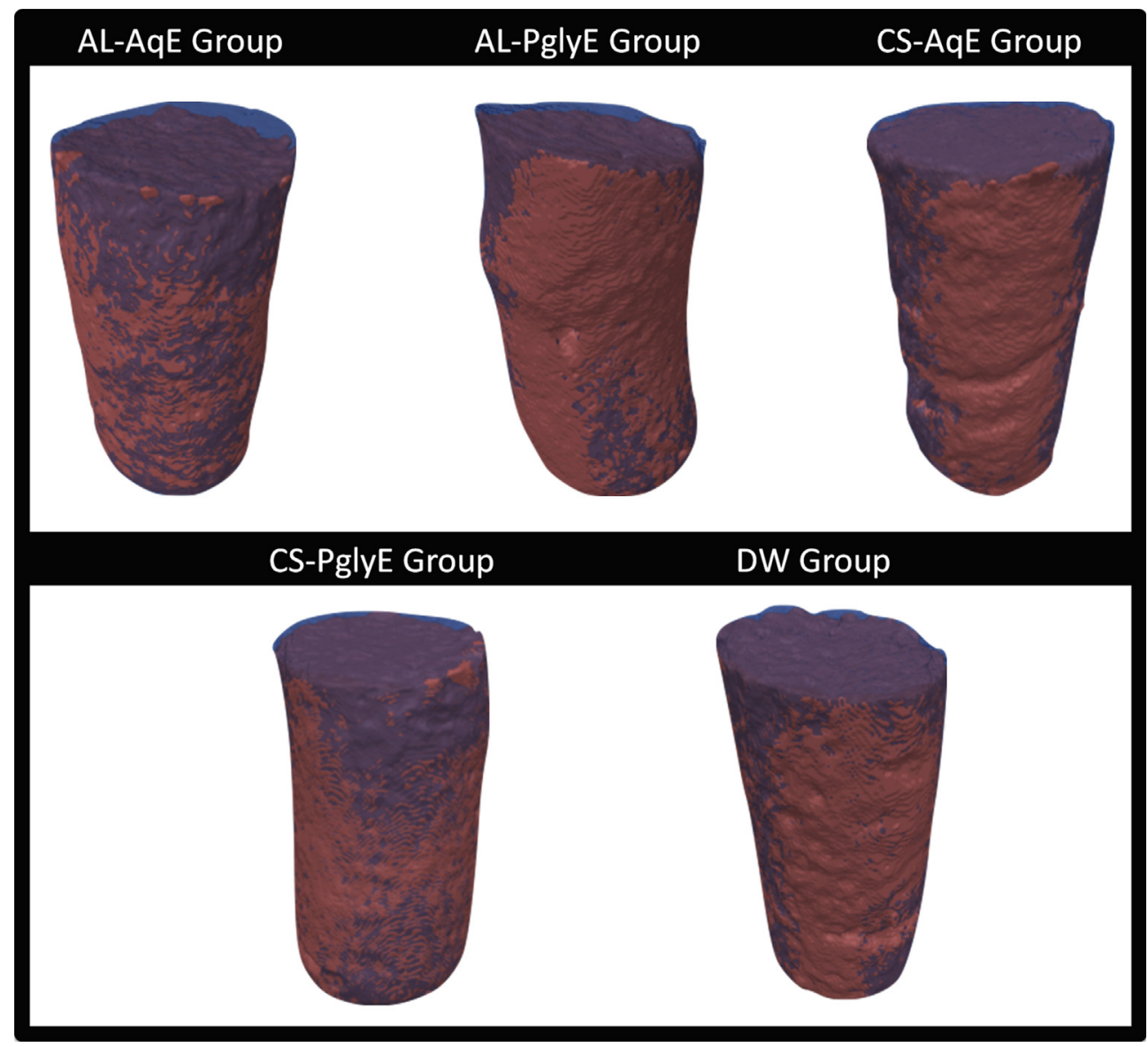

Figure 1. Representative micro-computed tomography tridimensional samples superimposed of initial (red) and after 168 hours of water immersion (blue) of AL-AqE, AL-PglyE, CS-AqE, CS-PglyE, and DW groups.

removed, and $800 \mu \mathrm{L}$ of the $E$. faecalis suspension was added. The microtubes were centrifuged (Eppendorf 5417R, Hamburg, Germany) in sequence at $1400 \mathrm{~g}, 2000 \mathrm{~g}, 3600 \mathrm{~g}$, and $5600 \mathrm{~g}$ by using two 5 -minute cycles at $25^{\circ} \mathrm{C}$ for each speed. The bacterial solution was replaced between all centrifugation cycles. At the end of the 8 cycles previously mentioned, the microtube suspensions were replaced by $800 \mu \mathrm{L}$ sterile $\mathrm{BHI}$ and were incubated at $37^{\circ} \mathrm{C}$ for 24 hours.

On day 2, the samples were agitated in a vortex (Vortex-mix VX200; Labnet, Edison, NJ), the BHI solution was then removed, and $800 \mu \mathrm{L}$ sterile $\mathrm{BHI}$ was added to each microtube. A single centrifugation cycle at $3600 \mathrm{~g}$ was performed at $25^{\circ} \mathrm{C}$ for 5 minutes, and the microtubes were incubated at $37^{\circ} \mathrm{C}$ for 24 hours.

On day 3 , the procedures were the same as those performed on day 1. On day 4, the procedures were the same as those on day 2.

On day 5 , the dentin specimens were removed from the BHI suspension; MTA was manipulated according to the 5 experimental groups $(n=10)$ and inserted with an MTA carrier device to entirely fill the root canal lengths. Ten additional specimens without cement formed the control group. The specimens were incubated at $37^{\circ} \mathrm{C}$ for 24 and 168 hours.

\section{Microscopic Analysis}

After each experimental period, the respective specimens were sectioned longitudinally with a precision diamond saw under sterile saline solution cooling. Sample sections were immersed in 17\% EDTA solution for 5 minutes and then in sterile saline solution.

A hemisection of each specimen was selected and stained with $30 \mu \mathrm{L}$ fluorescent LIVE/DEAD BacLight Bacterial Viability stain (Invitrogen Molecular Probes, Eugene, OR) for 10 minutes. The samples were examined with a confocal laser scanning microscope (Leica TCS-SPE; Leica Microsystems $\mathrm{GmbH}$, Mannheim, Germany) at $\times 40$

TABLE 1. Mean and Standard Deviation of Initial and Final Setting Times (Minutes), Flowability (Millimeters), and Volumetric Change (Percentage) for Tested Groups

\begin{tabular}{lcccc}
\hline Group & Initial setting time & Final setting time & Flowability & Volumetric change \\
\hline AL-AqE & $32^{\mathrm{a}} \pm 2.28$ & $79^{\mathrm{a}} \pm 2.65$ & $39.74^{\mathrm{a}} \pm 1.94$ & $1.47^{\mathrm{a}} \pm 1.14$ \\
AL-PglyE & $73^{\mathrm{b}} \pm 1.30$ & $177^{\mathrm{b}} \pm 2.59$ & $44.68^{\mathrm{b}} \pm 1.84$ & $2.60^{\mathrm{a}} \pm 1.79$ \\
CS-AqE & $46^{\mathrm{c}} \pm 4.28$ & $106^{\mathrm{c}} \pm 4.22$ & $39.29^{\mathrm{a}} \pm 0.79$ & $1.84^{\mathrm{a}} \pm 0.89$ \\
CS-PglyE & $60^{\mathrm{d}} \pm 4.51$ & $185^{\mathrm{d}} \pm 4.16$ & $47.72^{\mathrm{b}} \pm 1.24$ & $2.01^{\mathrm{a}} \pm 0.79$ \\
DW & $31^{\mathrm{a}} \pm 4.51$ & $60^{\mathrm{a}} \pm 6.69$ & $37.52^{\mathrm{a}} \pm 0.35$ & $1.17^{\mathrm{a}} \pm 0.71$ \\
\hline
\end{tabular}

Different letters in each column indicate statistical differences $(P<.05)$. 


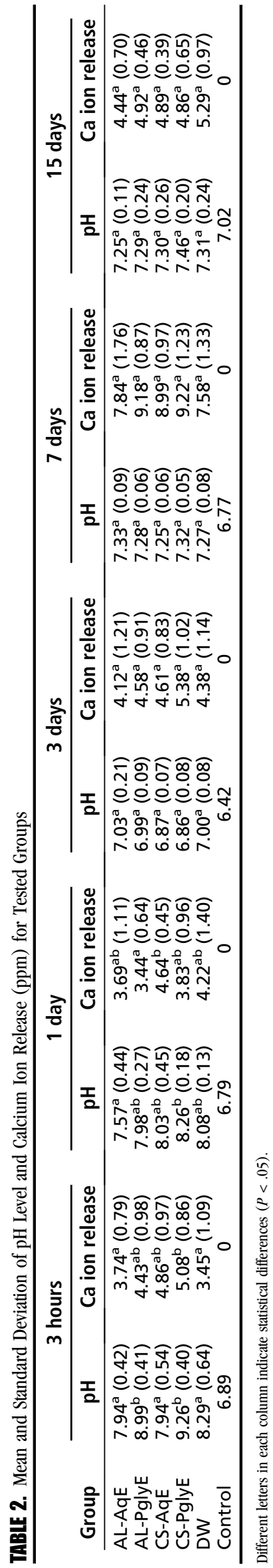

magnification. Six sequential images of the root canal interface in contact with cement were captured for each sample.

The confocal images were analyzed by bioImage $L$ software, which generated the percentages and biovolume of live and dead bacteria on the basis of green and red fluorescence, respectively.

\section{Surgical Procedures \\ Biological Evaluation}

Seventy-five healthy adult male Wistar rats (Rattus norvegicus albinus) weighing $250 \pm 50 \mathrm{~g}$ (Ethical approval CEEPA 028/2011) were anesthetized with intramuscular ketamine/xylazine $(0.1 \mathrm{~mL} / 100 \mathrm{~g})$. Each animal received 1 alveolar and 2 randomly distributed subcutaneous implants of the different groups.

The cements were inserted into sterile polyethylene tubes with $1.5 \mathrm{~mm}$ internal diameter and $10 \mathrm{~mm}$ long, which were immediately inserted into subcutaneous tissue in the medial dorsal region, followed by tissue suture (nonresorbable silk 4-0).

The maxillary left incisors were extracted, cements placed in tube implants (sterile polyethylene tubes, $1 \mathrm{~mm} \emptyset$ and $3 \mathrm{~mm}$ long, with 1 extremity sealed with gutta-percha) were inserted into the socket, and gingival tissue was sutured. The control group received empty tubes.

After 15, 30, and 60 days, the animals were killed by anesthetic overdose. The subcutaneous tissues with tubes were removed and immersed in 10\% buffered formalin for 48 hours. The left hemimaxillae were collected, immediately frozen in liquid nitrogen, and stored at $-80^{\circ} \mathrm{C}$.

\section{Subcutaneous Histologic Processing and Analysis}

After fixation, the tubes were removed from the tissue for standard histologic processing. For each sample, a total of 12 semi-serial 5-umthick sections obtained in the longitudinal direction of the tube space were stained with hematoxylin-eosin.

Six histologic sections of each sample were selected for histomorphometric analysis in 6 different microscopic fields of the fibrous capsular region in contact with cements. Lateral areas of the tube were used as control. A light microscope (Aristoplan; Leitz, Wetzlar, Germany) with $\times 100$ objective and klp $\times 8$ eyepiece (Carl Zeiss AG, Oberkochen, Germany) containing a 100-point integration grid (Zeiss II) was used to quantify (by the point volumetric method) the volume density or fraction (Vvi) of connective tissue (collagen fibers, fibroblasts, blood vessels) and inflammatory cells. The number of points coinciding with each cell $(\mathrm{Pi})$ and total points analyzed $(\mathrm{P})$ were determined to calculate the percentage of structures, thus calculating the Vvi by the formula: $\mathrm{Vvi}=(\Sigma \mathrm{Pi} / \Sigma \mathrm{P}) \times 100$.

\section{Cytokine Detection by Enzyme-linked Immunosorbent Assay}

Frozen maxillary samples, sprayed by a cryogenic mill $(6770$ Freezer/Mill; SPEX SamplePrep LLC, Metuchen, NJ ), were homogenized in phosphate-buffered saline solution containing protease inhibitor (SigmaFAST, St Louis, MO) and centrifuged at $2500 \mathrm{~g}\left(4^{\circ} \mathrm{C}\right.$ for 10 minutes). Tumor necrosis factor-alpha (TNF- $\alpha$ ) and interleukin (IL)-10 cytokine levels in the supernatants were measured by using enzyme-linked immunosorbent assay rat kits (R\&D Systems, Minneapolis, MN) according to the manufacturer's instructions, and the results are expressed as picograms of cytokine ( \pm standard deviation) per milligram of tissue. 
24 hours
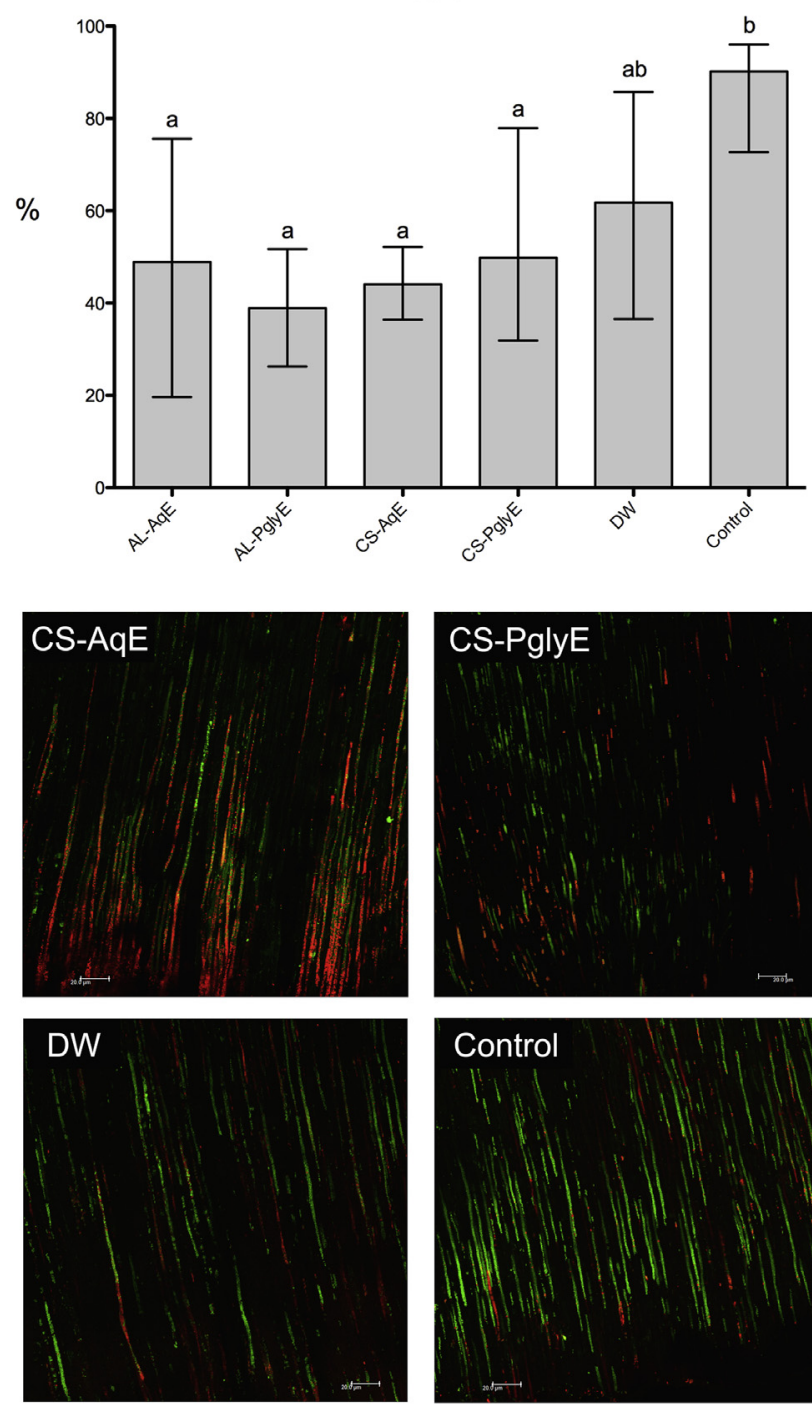
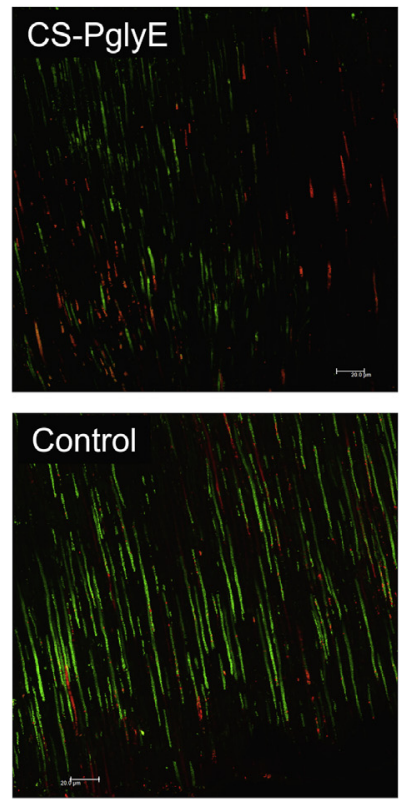
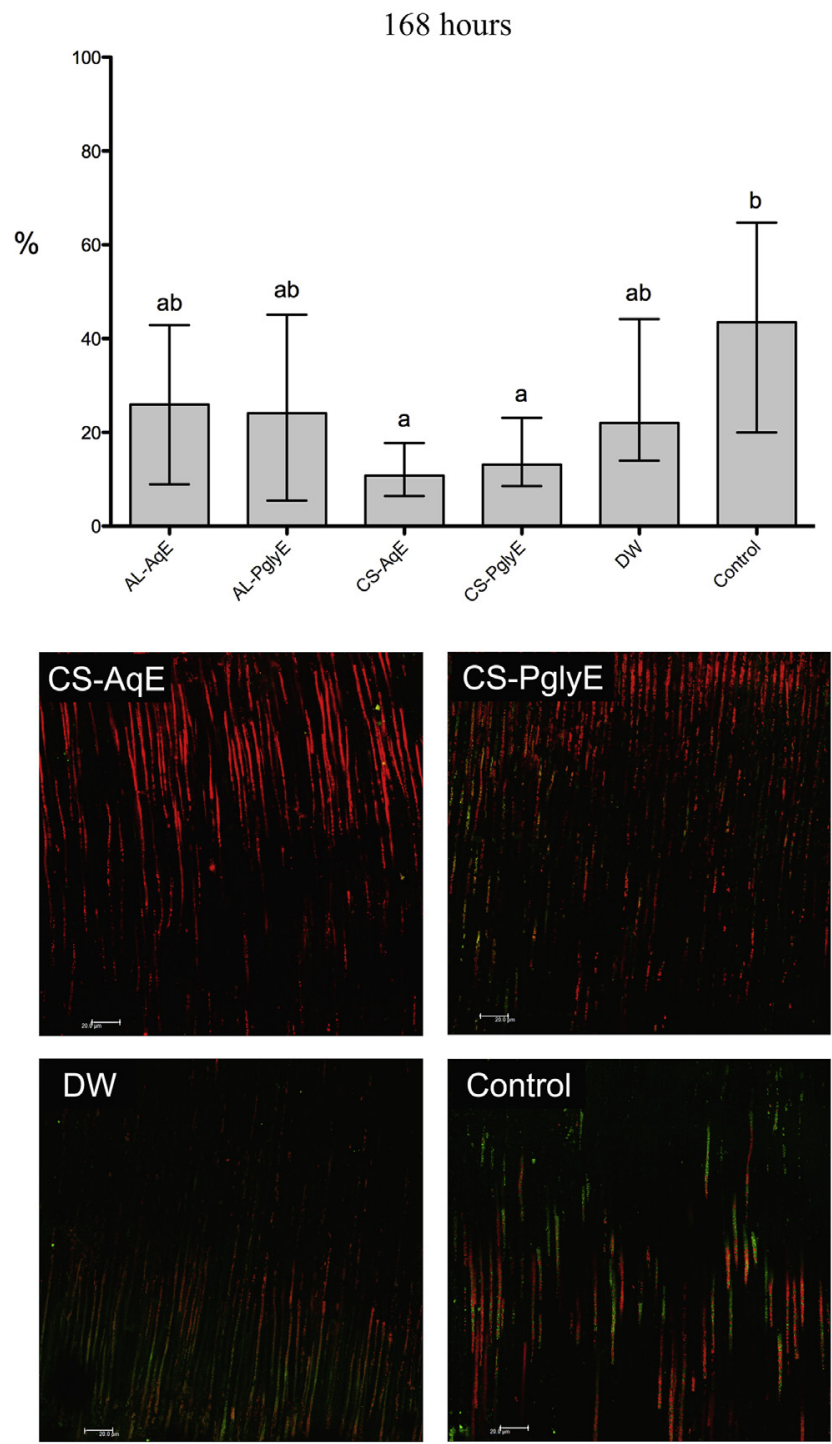

Figure 2. Graphic representation of median and ranges of percentages of bacterial viability after 24 and 168 hours. Different letters on bars represent statistical differences $(P<.05)$. Confocal laser scanning microscopy images of representative samples (CS-AqE, CS-PglyE, DW, and Control groups) showed viable (green) and dead (red) bacterial cells after the 2 periods. Bars represent $20 \mu \mathrm{m}$.

\section{Statistical Analysis}

The setting time, flowability, volumetric change, $\mathrm{pH}$ data, and histologic subcutaneous tissue evaluation were compared by the analysis of variance and Tukey tests. The calcium ion release, bacterial viability, and cytokine levels were analyzed by the Kruskal-Wallis and Dunn tests. A 5\% significance level was set, and Prism 5.0 software (GraphPad Software Inc, La Jolla, CA) was used for analyses.

\section{Physicochemical Tests}

Except for AL-AqE, all vehicles promoted changes in the white MTA initial setting time ranging from 32 to 73 minutes. All phytotherapy product groups increased $(P<.05)$ the final setting time $(79$ to $185 \mathrm{mi}-$ nutes) compared with DW (60 minutes). PglyE groups showed significantly greater flowability (from 44 to $47 \mathrm{~mm}$ ) compared with $\mathrm{AqE}$ groups (from 37 to $39 \mathrm{~mm}$ ). As shown in Figure 1, all groups showed similar volume loss (from $1.17 \%$ to $2.60 \%$ ). Table 1 shows the results of the abovementioned properties.
Table 2 represents the $\mathrm{pH}$ level and calcium ion release results. Alkaline $\mathrm{pH}$ was observed for all samples (range, 6.87-9.26). Only the CS-PglyE group showed increased $(P<.05)$ calcium ion release $(5.08 \mathrm{ppm})$ compared with DW $(3.45 \mathrm{ppm})$ for a 3-hour period. However, after the 3-day period, there was no significant difference in $\mathrm{pH}$ level and calcium ion release values between the groups.

\section{Antimicrobial Evaluation}

After the 24-hour period, only the DW group showed no significant reduction in bacterial viability $(61.77 \%)$ compared with the control group (90.18\%). However, after 168 hours, only CS extracts showed fewer $(P<.05)$ viable bacteria $(10.78 \%$ and $13.12 \%$, CS-AqE and CS-PglyE, respectively) compared with the control group (43.50\%). Figure 2 shows representative confocal images of the groups evaluated at 24 and 168 hours.

\section{Biological Evaluation}

Generally, the specimens evaluated showed a fibrocellular structural formation involving the implanted tube both laterally and at the 
extremity in contact with the cements. In initial periods, the experimental groups presented a thin connective tissue capsule that was permeated by inflammatory infiltrate, predominantly characterized by mononuclear cells. There was some blood vessel formation and presence of dispersed giant cells in some specimens as well as the presence of extruded material, characterized by amorphous structures. Over time, the evolution of repair was observed, with reduced inflammatory infiltrate and connective tissue maturation. Inflammatory infiltrate density was similar for all plant extracts groups compared with the distilled water group in all experimental periods. Table 3 presents the inflammatory infiltrate and connective tissue percentages after 15, 30, and 60 days. Figure 3 shows representative sections of groups in each period of analysis.

Alveolar bone repair showed a similar cytokine response pattern, because none of the associations with MTA modulated proinflammatory (TNF- $\alpha$ ) and anti-inflammatory cytokine (IL-10) production for both experimental periods (Table 4).

\section{Discussion}

Despite the recommendation to use $\mathrm{DW}$, other substances have been mixed with MTA to improve its working consistency and increase its antimicrobial effect $(11,22)$. Chlorhexidine significantly increased MTA's antibacterial effect but reduced its compressive strength (10) and increased its cytotoxicity (14).

Arctium lappa $\mathrm{L}$. and Casearia sylvestris SW extracts are widely used in folk medicine for their antibacterial and antiinflammatory properties (16-20), but no associations with MTA have been reported. In this study, AqE of each substance were used instead of DW for handling MTA. The 3:1 powder to liquid ratio was used because it favored satisfactory physicochemical properties of white MTA (23). Propylene glycol was used as the extraction solution because this substance improved the working consistency of MTA in the proportion of $80 \% \mathrm{DW}$ and $20 \%$ propylene glycol (8). The cements mixed with PglyE showed longer initial and final setting times and increased flowability, which are similar to the results published in another study (8). However, all the vehicles tested significantly altered MTA's final setting times. In the reference group in which DW was used, other authors $(8,24,25)$ found a shorter setting time. This difference can be related to the manipulation of the cement, when considering the aggregation, because at this stage there is a great possibility of variability in the hydration of the cement (22).

To evaluate solubility, studies usually adopt standards based on the difference in cement weight before and after immersion in water $(22,24)$. Solubility testing based on sample weights has limitations, especially regarding cement defragmentation and water absorption (22). Therefore, volumetric micro-computed tomography methodology was selected for this study (23), which used samples closer to clinical condition and only radiopaque material was evaluated. This method showed no difference between the groups and less than 3\% reduction in volume, as found in the control group of a previous study that used the same methodology (23) or by using the ISO standard (25). None of the extracts harmed the cement's ability to maintain an alkaline $\mathrm{pH}$ and calcium ion release $(8,23,25)$, properties responsible for MTA bioactivity (26).

Several studies have evaluated the antimicrobial effects of MTA against various microorganisms $(10,11,22,27,28)$. E. faecalis, mainly present in secondary endodontic infections (12), exhibits rapid growth and the ability to penetrate into and colonize dentinal tubules (29) and attach to collagen (30). Some experimental models have suggested using bovine dentin contaminated with $E$. faecalis and evaluated 

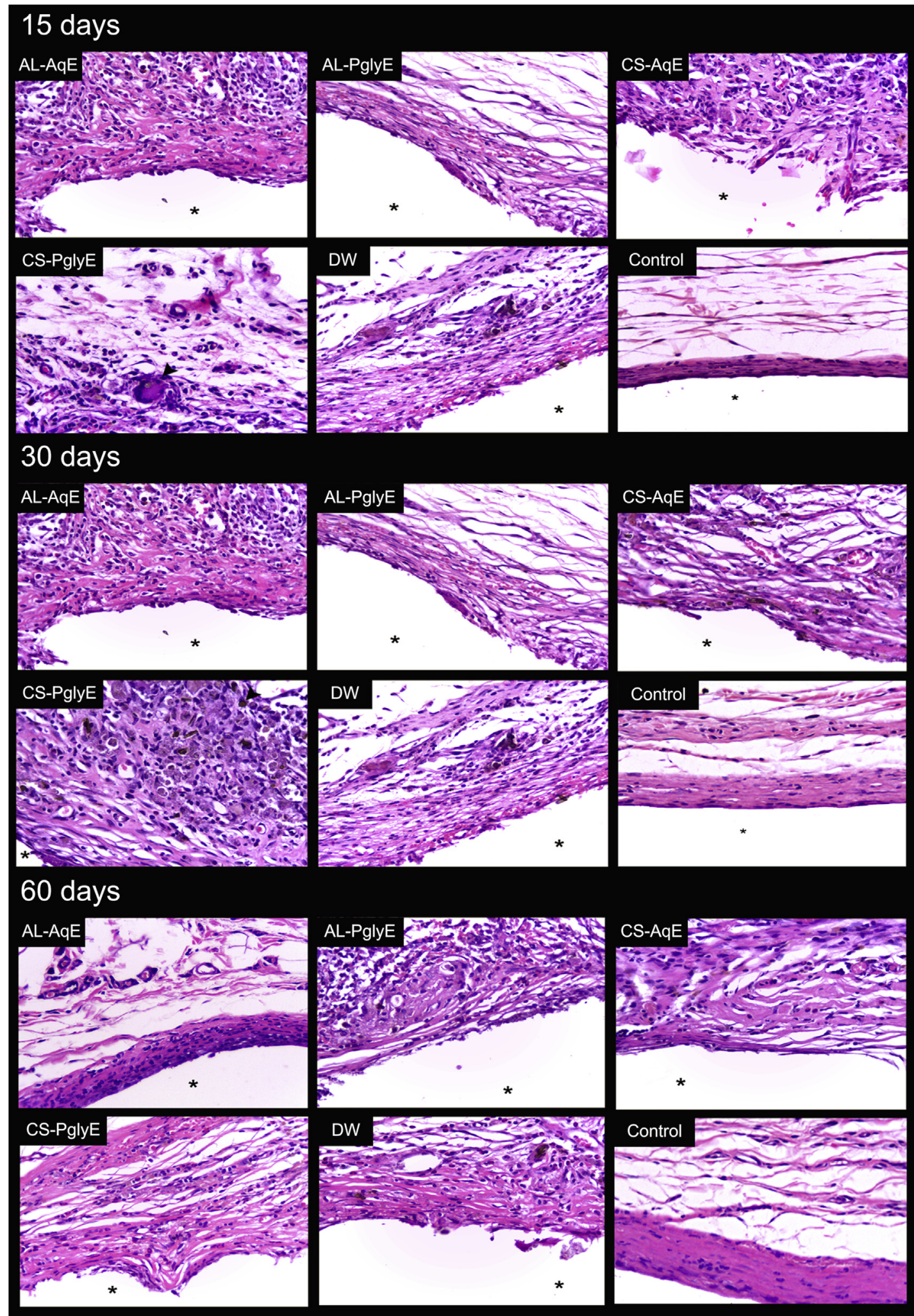

Figure 3. Representative histologic images (original magnification, $\times 40$ ) of connective tissue and inflammatory infiltrate around extremity of implanted sample tubes at 15,30 , and 60 days. The asterisk (*) represents the area of the implants.

by confocal laser scanning microscopy $(21,31)$ because the immunofluorescence technique is effective for detecting bacterial viability in dentinal tubules (32). However, this method has never been applied for the evaluation of MTA.
All extracts increased the cement antimicrobial effect after 24 hours, and only CS extracts significantly reduced bacterial viability compared with the control group after 168 hours. Furthermore, the cement manipulated with DW showed no notable antimicrobial effect, 
TABLE 4. Median and Interquartile Range of Cytokine Levels $(\mathrm{pg} / \mathrm{mg})$ in Alveolar Tissue Detected by Enzyme-linked Immunosorbent Assay

\begin{tabular}{llccc}
\hline \multicolumn{1}{c}{ Group } & TNF- $\alpha, \mathbf{1 5}$ days & TNF- $\alpha, 30$ days & IL-10, 15 days & IL-10, 30 days \\
\hline AL-AqE & $8.89(4.35-8.93)$ & $3.37(2.15-5.95)$ & $11.85(6.99-13.34)$ & $14.19(8.65-29.80)$ \\
AL-PglyE & $5.00(3.63-9.22)$ & $3.19(2.05-4.07)$ & $10.93(6.14-12.10)$ & $10.78(9.68-11.44)$ \\
CS-AqE & $5.91(3.94-9.55)$ & $5.57(4.95-6.10)$ & $14.16(6.00-19.23)$ & $8.79(6.78-9.37)$ \\
CS-PglyE & $6.13(5.32-7.22)$ & $4.86(2.25-6.90)$ & $7.77(5.62-8.99)$ & $10.62(8.54-24.32)$ \\
DW & $6.17(5.44-9.82)$ & $3.97(2.74-4.91)$ & $12.25(5.34-13.76)$ & $18.88(16.00-24.68)$ \\
Control & $4.11(3.98-4.35)$ & $2.56(1.87-3.02)$ & $5.30(4.39-5.52)$ & $8.53(8.49-11.88)$ \\
\hline
\end{tabular}

No statistical differences $(P<.05)$ were found among groups for TNF- $\alpha$ and IL-10 in different periods.

because in all studied periods, no significant difference was shown compared with the positive control group.

The biocompatibility of cements was assessed by the widely used method of rat subcutaneous implantation $(25,33)$. MTA exhibited lowintensity inflammatory infiltrate that diminished over time, whereas connective tissue increased with time (34). No plant extracts significantly reduced the inflammatory infiltrate, although they showed antiinflammatory properties $(18,19)$.

Two cytokines with opposing roles in regulating immune and inflammatory responses at alveolar bone repair sites were also evaluated. All groups showed peak proinflammatory cytokine TNF- $\alpha$ expression at 15 days, diminishing in the following period, whereas anti-inflammatory mediator IL-10 was produced in a reverse pattern. TNF- $\alpha$ plays a central role in inflammatory responses by mediating inflammatory cell chemoattraction, modulating both precursor cell and mature osteoblast formation, and osteoclast activity (35). Conversely, IL-10 inhibits inflammatory and osteoclastogenic factor production, indirectly contributing to bone formation.

\section{Conclusion}

Casearia sylvestris extracts increased MTA's antimicrobial effect without influencing its biocompatibility but interfered in some of its physicochemical properties.

\section{Acknowledgments}

This work was supported by FAPESP (2011/18272-1). The authors deny any conflicts of interest related to this study.

\section{References}

1. Torabinejad M, Watson TF, Pitt Ford TR. Sealing ability of a mineral trioxide aggregate when used as a root end filling material. J Endod 1993;19:591-5.

2. Gandolfi MG, Sauro S, Mannocci F, et al. New tetrasilicate cements as retrograde filling material: an in vitro study on fluid penetration. J Endod 2007:33:742-5.

3. Torabinejad M, Smith PW, Kettering JD, et al. Comparative investigation of marginal adaptation of mineral trioxide aggregate and other commonly used root-end filling materials. J Endod 1995;21:295-9.

4. Camilleri J, Pitt Ford TR. Mineral trioxide aggregate: a review of the constituents and biological properties of the material. Int Endod J 2006;39:747-54.

5. Shahi S, Rahimi S, Lotfi M, et al. A comparative study of the biocompatibility of three root-end filling materials in rat connective tissue. J Endod 2006;32:776-80.

6. Holland R, de Souza V, Nery MJ, et al. Reaction of rat connective tissue to implanted dentin tubes filled with mineral trioxide aggregate or calcium hydroxide. J Endod 1999;25:161-6.

7. Danesh F, Tootian Z, Jahanbani J, et al. Biocompatibility and mineralization activity of fresh or set white mineral trioxide aggregate, biomimetic carbonated apatite, and synthetic hydroxyapatite. J Endod 2010;36:1036-41.

8. Duarte MA, Alves de Aguiar K, Zeferino MA, et al. Evaluation of the propylene-glycol association on some physical and chemical properties of mineral trioxide aggregate. Int Endod J 2012;45:565-70.

9. Formosa LM, Mallia B, Camilleri J. A quantitative method for determining the antiwashout characteristics of cement-based dental materials including mineral trioxide aggregate. Int Endod J 2013;46:179-86.

10. Holt DM, Watts JD, Beeson TJ, et al. The anti-microbial effect against enterococcus faecalis and the compressive strength of two types of mineral trioxide aggregate mixed with sterile water or 2\% chlorhexidine liquid. J Endod 2007;33:844-7.
11. Estrela C, Bammann LL, Estrela CR, et al. Antimicrobial and chemical study of MTA, Portland cement, calcium hydroxide paste, Sealapex and Dycal. Braz Dent J 2000; 11:3-9.

12. Sundqvist G, Figdor D, Persson S, et al. Microbiologic analysis of teeth with failed endodontic treatment and the outcome of conservative re-treatment. Oral Surg Oral Med Oral Pathol Oral Radiol Endod 1998;85:86-93.

13. Peters LB, Wesselink PR, Buijs JF, et al. Viable bacteria in root dentinal tubules of teeth with apical periodontitis. J Endod 2001;27:76-81.

14. Hernandez EP, Botero TM, Mantellini MG, et al. Effect of ProRoot MTA mixed with chlorhexidine on apoptosis and cell cycle of fibroblasts and macrophages in vitro. Int Endod J 2005;38:137-43.

15. Kogan P, He J, Glickman GN, et al. The effects of various additives on setting properties of MTA. J Endod 2006;32:569-72.

16. Schneider NFZ, Moura NF, Colpo T, et al. Chemical composition and antimicrobial activity of the volatile oil of Casearia sylvestris Swart. Rev Bras Farm 2006;87:112-4.

17. Gentil M, Pereira JV, Sousa YT, et al. In vitro evaluation of the antibacterial activity of Arctium lappa as a phytotherapeutic agent used in intracanal dressings. Phytother Res 2006;20:184-6.

18. Esteves I, Souza IR, Rodrigues M, et al. Gastric antiulcer and anti-inflammatory activities of the essential oil from Casearia sylvestris Sw. J Ethnopharmacol 2005;101:191-6.

19. Zhao F, Wang L, Liu K. In vitro anti-inflammatory effects of arctigenin, a lignan from Arctium lappa L., through inhibition on iNOS pathway. J Ethnopharmacol 2009;122: 457-62.

20. Albano MN, da Silveira MR, Danielski LG, et al. Anti-inflammatory and antioxidant properties of hydroalcoholic crude extract from Casearia sylvestris Sw. (Salicaceae). J Ethnopharmacol 2013;147:612-7.

21. Andrade FB, Arias MP, Maliza AG, et al. A new improved protocol for in vitro intratubular dentinal bacterial contamination for antimicrobial endodontic tests: standardization and validation by confocal laser scanning microscopy. J Appl Oral Sci 2015;23:591-8.

22. Parirokh M, Torabinejad M. Mineral trioxide aggregate: a comprehensive literature review-part I: chemical, physical, and antibacterial properties. J Endod 2010;36:16-27.

23. Cavenago BC, Pereira TC, Duarte MAH, et al. Influence of powder-to-water ratio on radiopacity, setting time, $\mathrm{pH}$, calcium ion release and a micro-CT volumetric solubility of white mineral trioxide aggregate. Int Endod J 2014;47:120-6.

24. Vivan RR, Zapata RO, Zeferino MA, et al. Evaluation of the physical and chemical properties of two commercial and three experimental root-end filling materials. Oral Surg Oral Med Oral Pathol Oral Radiol Endod 2010;110:250-6.

25. Marciano MA, Guimarães BM, Amoroso-Silva P, et al. Physical and chemical properties and subcutaneous implantation of mineral trioxide aggregate mixed with propylene glycol. J Endod 2016;42:474-9.

26. Gandolfi MG, Taddei P, Tinti A, et al. Apatite-forming ability (bioactivity) of ProRoot MTA. Int Endod J 2010;43:917-29.

27. Morgental RD, Vier-Pelisser FV, Oliveira SD, et al. Antibacterial activity of two MTAbased root canal sealers. Int Endod J 2011;44:1128-33.

28. Alsalleeh F, Chung N, Stephenson L. Antifungal activity of endosequence root repair material and mineral trioxide aggregate. J Endod 2014;40:1815-9.

29. Orstavik D, Haapasalo M. Disinfection by endodontic irrigants and dressings of experimentally infected dentinal tubules. Endod Dent Traumatol 1990;6:142-9.

30. Love RM. Enterococcus faecalis: a mechanism for its role in endodontic failure. Int Endod J 2001;34:399-405.

31. Ma J, Wang Z, Shen Y, et al. A new noninvasive model to study the effectiveness of dentin disinfection by using confocal laser scanning microscopy. J Endod 2011;37: $1380-5$.

32. Zapata RO, Bramante CM, de Moraes IG, et al. Confocal laser scanning microscopy is appropriate to detect viability of Enterococcus faecalis in infected dentin. J Endod 2008;34:1198-201.

33. Yaltirik M, Ozbas H, Bilgic B, et al. Reactions of connective tissue to mineral trioxide aggregate and amalgam. J Endod 2004;30:95-9.

34. Holland R, Souza V, Nery MJ, et al. Reaction of rat connective tissue to implanted dentin tubes filled with a white mineral trioxide aggregate. Braz Dent J 2002;13:23-6.

35. Graves DT, Cochran D. The contribution of interleukin- 1 and tumor necrosis factor to periodontal tissue destruction. J Periodontol 2003;74:391-401. 